\title{
QUALIDADE FISIOLÓGICA DE GENÓTIPOS DE TOMATE FERTILIZADOS COM LODO DE ESGOTO
}

\author{
FÁVARIS, Nathália Aparecida Bragança ${ }^{1}$ \\ LOPES, José Carlos ${ }^{1}$ \\ FREITAS, Allan Rocha de ${ }^{1}$ \\ ZANOTTI, Rafael Fonseca ${ }^{1}$ \\ MONTEIRO, Carla Basilio ${ }^{1}$
}

\begin{abstract}
RESUMO: A análise do potencial fisiológico de sementes é essencial para o conhecimento do desempenho do lote de sementes na fase de propagação. Considerado como um material de grande potencial de impacto ambiental, o lodo de esgoto vem se destacando como insumo agrícola, podendo conter diversos teores de nutrientes. Objetivou-se com este trabalho analisar o crescimento inicial de plântulas de cultivares de tomate (Solanum lycopersicum L.) em substrato composto por biossólidos. Foram utilizadas sementes de tomate (Solanum lycopersicum L.) das cultivares 'Cereja Carolina' e 'Cereja Samambaia' sobre seis substratos compostos com areia e lodo de esgoto, sendo: areia pura (testemunha); areia + lodo $\left(20 \mathrm{t} \mathrm{ha}^{-1}\right)$; areia + lodo $\left(80 \mathrm{t} \mathrm{ha}^{-1}\right)$; areia + lodo $\left(160 \mathrm{t} \mathrm{ha}^{-1}\right)$; areia + lodo $\left(320 \mathrm{t} \mathrm{ha}^{-1}\right)$; e areia + lodo $\left(520 \mathrm{t} \mathrm{ha}^{-1}\right)$. Cada parcela experimental foi composta por quatro repetições de 25 sementes. Foram analisados: emergência (\%), índice de velocidade de emergência (IVE), comprimento de parte aérea (mm) e da raiz $(\mathrm{mm})$, massas fresca e seca das plântulas (mg plântula). Verificou-se que a cultivar 'Cereja Samambaia' apresentou médias superiores à cultivar 'Cereja Carolina' para as variáveis massas fresca e seca das plântulas. A maior produção das massas fresca e seca ocorre com uso do lodo de esgoto na concentração entre $362 \mathrm{t} \mathrm{ha}^{-1} \mathrm{e} 485 \mathrm{t} \mathrm{ha}^{-1}$.
\end{abstract}

Palavras-chave: Solanum lycopersicum L. Massa orgânica. Resíduo. Crescimento inicial.

SUMMMARY: The analysis of physiological potential of seeds is essential to the knowledge of the seed lot performance in the propagation phase. Considered with a great potential environmental impact material, the sewage sludge has emerged as agricultural input, and may contain different amounts of nutrients. The objective of this work to analyze the initial growth of seedlings of tomato cultivars (Solanum Lycopersicum L.) in substrate composed of biosolids. Tomato seeds were used (Solanum lycopersicum L.) cultivars 'Cherry Carolina "and" Cherry Fern' over six substrates compounds with sand and sewage sludge, as follows: pure sand (control); sand + sludge $\left(20 \mathrm{t} \mathrm{ha}^{-1}\right)$; sand $+^{-1}$ sludge $\left(80 \mathrm{t} \mathrm{ha}^{-1}\right)$; sand + sludge $\left(160 \mathrm{t} \mathrm{ha}^{-1}\right)$; sand + sludge $\left(320 \mathrm{t} \mathrm{ha}^{-1}\right)$; and sand + sludge $\left(520 \mathrm{t} \mathrm{ha}^{-1}\right)$. Each plot consisted of four replications of 25 seeds. They were analyzed: emergency (\%), emergency velocity index (EVI), shoot length $(\mathrm{mm})$ and root $(\mathrm{mm})$, fresh and dry weight of seedlings (mg seedlings). It was found that the cultivar 'Cherry Fern' showed average higher than the cultivar 'Cherry Carolina' for the variable fresh and dry weight of seedlings. The highest yield of fresh and dry weight occurs with use of sewage sludge in concentrations between 362 $\mathrm{t} \mathrm{ha}^{-1}$ and $485 \mathrm{t} \mathrm{ha}^{-1}$.

Keywords: Solanum lycopersicum L. Organic mass. Waste. Initial growth.

\section{INTRODUÇÃO}

O tomateiro (Solanum lycopersicon), uma das hortaliças mais produzidas no Brasil e no mundo, é uma planta eudicotiledônea da ordem Tubiflora e, pertencente à família Solanaceae, planta herbácea perene, mas que se comporta como anual desde a semeadura até a produção de sementes. Devido à sua

\footnotetext{
${ }^{1}$ Centro de Ciências Agrárias da Universidade Federal do Espírito Santo (UFES). Departamento de Produção Vegetal
} 
adaptação às condições climáticas do Brasil, por ser facilmente cultivado em praticamente todos os estados. A espécie cultivada, o Solanum lycopersicum L. (Tubiflorae: Solanaceae), é uma espécie cosmopolita e descendente da espécie selvagem, S. lycopersicum var. cerasiforme que produz frutos do tipo cereja (FILGUEIRA, 2013). Podem desenvolver-se em uma gama de latitudes, tipos de solo, temperatura e métodos de cultivo, destacando-se que os ambientes quentes, com boa iluminação e drenagem são os mais adequados para o seu cultivo (ALVARENGA, 2013).

O Brasil ocupa a oitava posição do ranking mundial na produção de tomate (Solanum lycopersicum L.) (FAO, 2015), destacando-se como uma cultura de grande importância social e econômica no Brasil, sendo que em 2015 a área cultivada foi de 62.782 hectares, com uma produção anual de 4.187.646 toneladas, cuja produtividade média foi de $66.802 \mathrm{t} \mathrm{ha}^{-1}$. A região Sudeste apresenta a maior produção de tomate de mesa, responsável por mais de $44 \%$ do total produzido, em que o estado de São Paulo participou com aproximadamente $45 \%$ da produção da região, e o estado do Espírito Santo contribuiu com uma produção de 144.844 toneladas, com uma área de 2.508 ha, cuja produtividade foi de $57.864 \mathrm{t} \mathrm{ha}^{-1}$ (AGRIANUAL, 2015; IBGE, 2016).

A produção de mudas de qualidade é uma das principais etapas do sistema produtivo cultural, e o método predominante de propagação de tomateiro é via sexuada, utilizando-se, principalmente, sementes híbridas de alta qualidade, o que determina uma elevação dos custos de implementação da cultura (NADAI et al., 2015). Sementes de alta qualidade são aquelas que apresentam atributos físicos, genéticos, fitossanitários e fisiológicos (McDONALD; COPELAND, 1997), principalmente, alto potencial fisiológico, que é caracterizado por meio da germinação e do vigor (MARCOS-FILHO, 2005).

Todavia, mudas de qualidade são aquelas sadias, bem desenvolvidas e uniformes, que apresentam menor vulnerabilidade aos estresses bióticos e abióticos, resultando em estandes mais homogêneos (FERREIRA et al., 2013). No entanto, nesta etapa de produção de mudas, dentre os insumos mais importantes para o crescimento inicial da planta, destaca-se o substrato, que apresenta grande influência na germinação das sementes e desempenha papel primordial, devendo apresentar boas condições físicas e químicas (DIAS et al., 2011; VENÂNCIO et al., 2012; CERQUEIRA, 2015; FREITAS et al., 2015).

Atualmente, com o impacto da crescente urbanização, muitos problemas ambientais estão sendo observados em diversos países, incluindo o Brasil, e em destaque a má disposição e acúmulo de resíduos industriais decorrentes das unidades de tratamentos de esgoto. Desta forma, pesquisas têm sido desenvolvidas com intuito de propor metodologias para amenizar os impactos negativos, pelo efeito acumulativo, e viabilizar sua utilização na agricultura, em virtude do potencial químico do lodo de esgoto como fonte de macro e micronutrientes em elevadas proporções, como fontes alternativas para suprir, total ou parcialmente, as necessidades nutricionais das espécies vegetais de interesse econômico e social (LOPES et al., 2005; PINTO et al., 2014; SOMAVILLA et al., 2014; FREITAS et al., 2015).

O lodo de esgoto por conter variados teores de diversos nutrientes pode ser utilizado como insumo agrícola, conforme observado por Oliveira et al. (2009), que estudando o lodo de esgoto no desenvolvimento inicial de duas cultivares de mamona em dois tipos de solo observaram aumento na fertilidade do solo, pela elevação dos teores de matéria orgânica, determinando incremento no crescimento e na produção de massa seca das plântulas.

A avaliação da disponibilidade dos elementos presentes nos resíduos industriais para que sejam absorvidos pelas plantas, seu respectivo acúmulo e efeito podem ser observados ao se utilizar substrato inerte ou com baixo teor de nutrientes, sendo recomendado o uso de areia lavada ou vermiculita (ALVES et al., 2008; BRASIL, 2009). 
Objetivou-se com este trabalho analisar a emergência e o crescimento inicial de plântulas de tomate (Solanum lycopersicum L.) dos cultivares 'Cereja Carolina' e 'Cereja Samambaia' em substrato composto por biossólidos.

\section{MATERIAL E MÉTODOS}

O estudo foi realizado no Laboratório de Análise de Sementes do Centro de Ciências Agrárias da Universidade Federal do Espírito Santo, localizado no município de Alegre, estado do Espírito Santo, situado a uma altitude de $277 \mathrm{~m}$, com coordenadas geográficas $20^{\circ} 45^{\prime} 49^{\prime \prime} \mathrm{S}$ e $41^{\circ} 31^{\prime} 58^{\prime \prime} \mathrm{W}$. Na condução deste trabalho foram utilizadas sementes de tomate (Solanum lycopersicum L.) dos cultivares 'Cereja Carolina' (Feltrin; lote: 0697100200) e 'Cereja Samambaia' (Topssed, lote: 020796), cada uma constituída por seis amostras do mesmo lote, procedentes do comércio local, que foram homogeneizadas, cuja germinação testada inicialmente em B.O.D foram entre 85 a $100 \%$.

O lodo de esgoto utilizado foi coletado na Estação de Tratamento de Esgoto (ETE) da Companhia Espírito Santense de Saneamento (CESAN) de Joana Dark, município de Vitória-ES, cujas análises físicoquímicas e de metais pesados revelaram valores de $\mathrm{pH} \mathrm{H}_{2} \mathrm{O}: 6,32$; umidade natural: 98,12\%; $\mathrm{N}: 21560 \mathrm{mg}$ $\mathrm{dm}^{-3}$; P: 856,24 mg dm${ }^{-3}$; Ca: $62756 \mathrm{mg} \mathrm{dm}^{-3}$; $\mathrm{Mg}: 291,6 \mathrm{mg} \mathrm{dm}^{-3}$; Cu: 571,5 mg dm${ }^{-3}$; Cr: 568,7 mg $\mathrm{dm}^{-3} ; \mathrm{Zn}: 1010,9 \mathrm{mg} \mathrm{dm}^{-3} ; \mathrm{Co}=8 \mathrm{mg} \mathrm{dm}^{-3} ; \mathrm{Ni}=25 \mathrm{mg} \mathrm{dm}^{-3} ; \mathrm{Cd}=3 \mathrm{mg} \mathrm{dm}^{-3} ; \mathrm{Pb}=80 \mathrm{mg} \mathrm{dm}^{-3} ; \mathrm{Hg}=1,5$ $\mathrm{mg} \mathrm{dm}{ }^{-3} ; \mathrm{Mn}=118 \mathrm{mg} \mathrm{dm}^{-3} ; \mathrm{Fe}=34 \mathrm{~g} \mathrm{dm}^{-3}$.

Os tratamentos consistiram em seis substratos compostos com areia e lodo de esgoto, peneirado em malhas de quatro milímetros, sendo: areia pura (testemunha); areia + lodo $\left(20 \mathrm{t} \mathrm{ha}^{-1}\right)$; areia + lodo (80 tha $\left.{ }^{1}\right)$; areia + lodo $\left(160 \mathrm{t} \mathrm{ha}^{-1}\right)$; areia + lodo $\left(320 \mathrm{t} \mathrm{ha}^{-1}\right)$; e areia + lodo $\left(520 \mathrm{t} \mathrm{ha}^{-1}\right)$.

$\mathrm{O}$ delineamento experimental foi o inteiramente casualizado (DIC), em um fatorial 2x6 (dois cultivares e seis substratos). Cada parcela experimental foi composta por quatro repetições. Foram dispostas 25 sementes em cada placa de Petri, semeadas a uma profundidade de aproximadamente $20 \mathrm{~mm}$ e mantidas em câmaras tipo B.O.D. (Biochemical Oxigen Demand), reguladas para o regime de temperatura constante de $25^{\circ} \mathrm{C}$, com fotoperíodo de oito horas, utilizando-se lâmpadas fluorescentes tipo luz do dia (4 x $20 \mathrm{~W})$.

Realizaram-se contagens diárias do número de plântulas emersas até a estabilização da emergência, considerando-se emersas as plântulas que apresentavam o hipocótilo com $2 \mathrm{~mm}$ acima do substrato. Com os dados obtidos foram determinadas as seguintes características: emergência (\%); índice de velocidade de emergência (IVE), adaptado segundo a fórmula proposta por Maguire (1962): $\operatorname{IVE}=\sum(\mathrm{n} / \mathrm{t}$ ), onde: $\mathrm{t}=$ número de dias da semeadura na primeira, segunda ... i-ésima contagem, respectivamente; comprimento de parte aérea $(\mathrm{mm})$ e da raiz $(\mathrm{mm})$, medidos com uma régua graduada em centímetros, medindo-se do colo ao ápice da plântula para a parte aérea e da altura do colo à extremidade da raiz, para o comprimento da raiz; massas fresca e seca das plântulas (mg plântula). O sistema radicular e a parte aérea foram secos em estufa de circulação forçada a $72{ }^{\circ} \mathrm{C}$, até atingirem peso constante, obtido em 72 horas, para posterior determinação da massa seca do sistema radicular e da parte aérea, sendo realizada a pesagem em balança analítica $(0,0001 \mathrm{~g})$.

Os dados referentes às características avaliadas foram transformados: emergência $\mathrm{Y}=$ [para arco seno $(\mathrm{x} / 100) 1 / 2]$ e as demais, pela [( $x+0,5) 1 / 2]$, observadas as pressuposições do teste de normalidade e de homogeneidade de variância e a análise de regressão. Para a análise dos dados foi utilizado o software $\mathrm{R}$ (R DEVELOPMENT CORE TEAM, 2013). 


\section{RESULTADO E DISCUSSÃO}

Neste trabalho foram utilizadas somente concentrações de lodo em areia lavada, que é inerte, como opção para melhor compreensão do efeito do biossólido sobre a emergência e crescimento inicial de plântulas de tomate.

A emergência das plântulas apresentou variação entre os substratos de $10 \%$ para o cultivar 'Cereja Samambaia' e 14\% para o cultivar 'Cereja Carolina'. Embora o cultivar 'Cereja Carolina' tenha apresentado valores numericamente superiores quando comparada o cultivar 'Cereja Samambaia', não houve diferenças significativas entre os substratos utilizados, sugerindo que não tenha ocorrido influência do lodo sobre a emergência e velocidade de emergência das plântulas (Figura 1A e 1B). Entretanto, a eficiência deste substrato em germinação e emergência já foi relatada para outras espécies como: feijão (LOBO et al., 2012); mamoneira (NASCIMENTO et al., 2011). E no presente estudo, a incorporação de areia objetivou melhorar a estrutura do biossólido como substrato, alterando suas características físicas, como em outros estudos, a utilização de condicionadores obtidos de resíduos orgânicos e para propiciar a boa formação de mudas, como: alface (LOPES et al., 2005); brócolis (LOPES et al., 2012); cupuaçu (ARAÚJO NETO et al., 2015); maracujá (FREITAS et al., 2015).

Nesta fase, o substrato é de fundamental importância, pois as suas características físicas, químicas e biológicas, como: estrutura, aeração, capacidade de retenção de água, grau de infestação de patógenos, dentre outros, devem oferecer as melhores condições para que haja uma excelente germinação e favoreça o desenvolvimento das mudas (PIÑA-RODRIGUES et al., 2007; BRASIL, 2009; SILVA; QUEIROZ, 2014).

A eficiência na translocação e absorção dos nutrientes presentes no substrato é definida com razão a biomassa produzida pela planta (AMARAL et al., 2011), condicionando a analisar a qualidade das fontes de nutrientes utilizadas sobre seu crescimento. A partir da análise química, verifica-se que todos os metais pesados presentes no lodo de esgoto utilizado se apresentavam abaixo do limites máximo determinado pela Conama (2006). 
Figura 1. Porcentagem de emergência (A), índice de velocidade de emergência (B), comprimento de parte aérea (C) e a raiz de plântulas (D), massa fresca (E) e massa seca das plântulas (F), de cultivares 'Cereja Samambaia' (C1) e 'Cereja Carolina' (C2) em função das concentrações de lodo de esgoto.

A

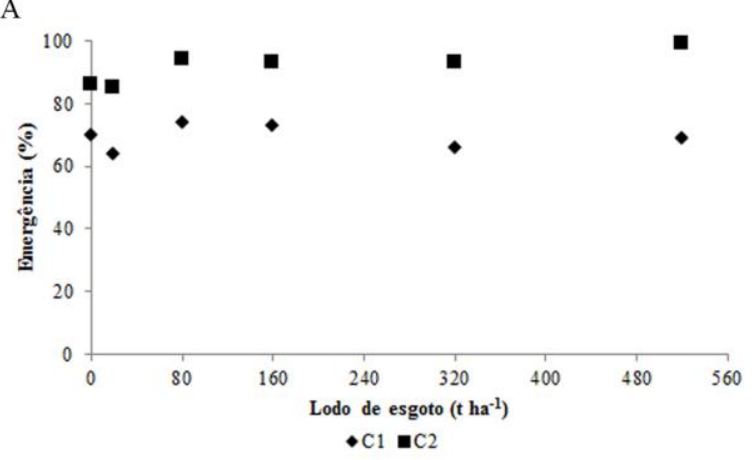

$\mathrm{C}$
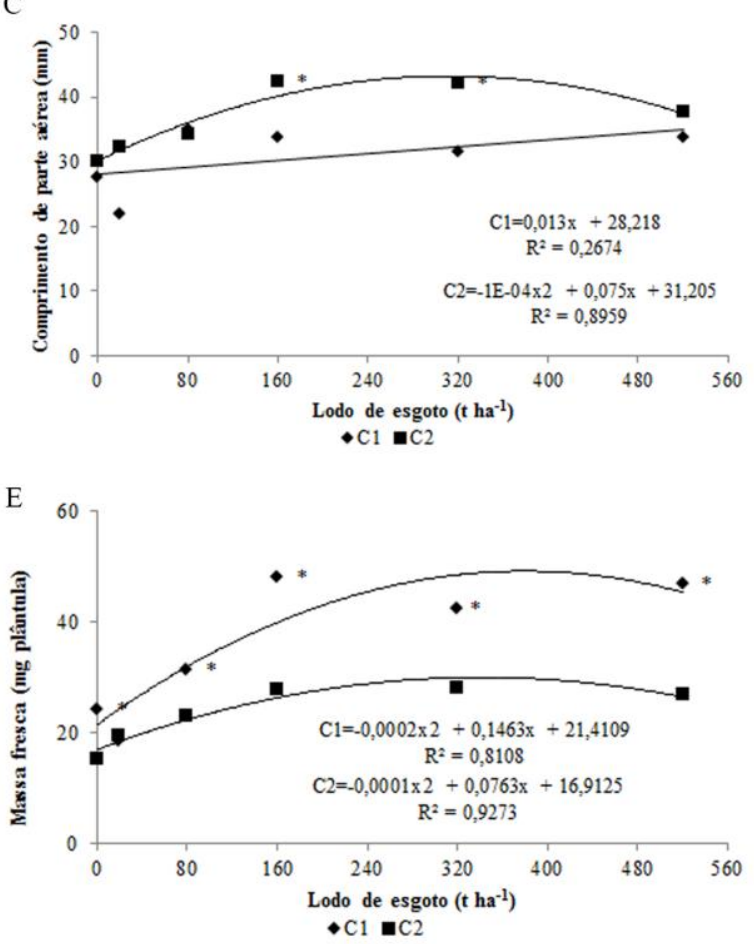

B

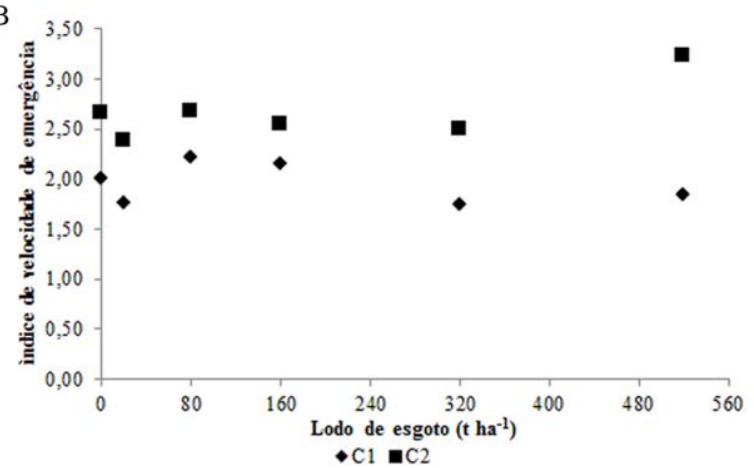

D

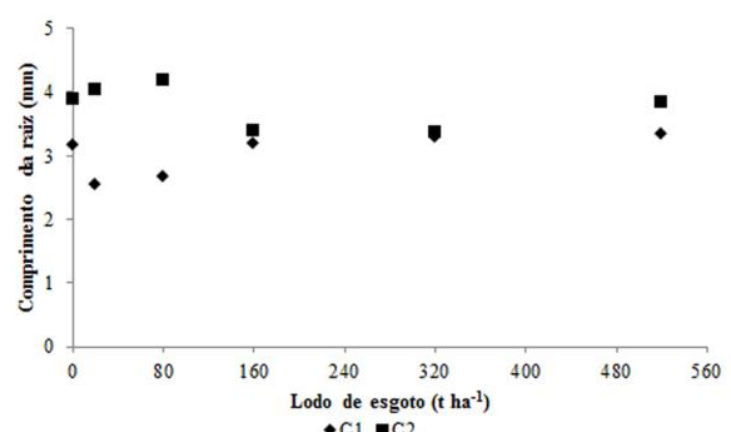

$\mathrm{F}$

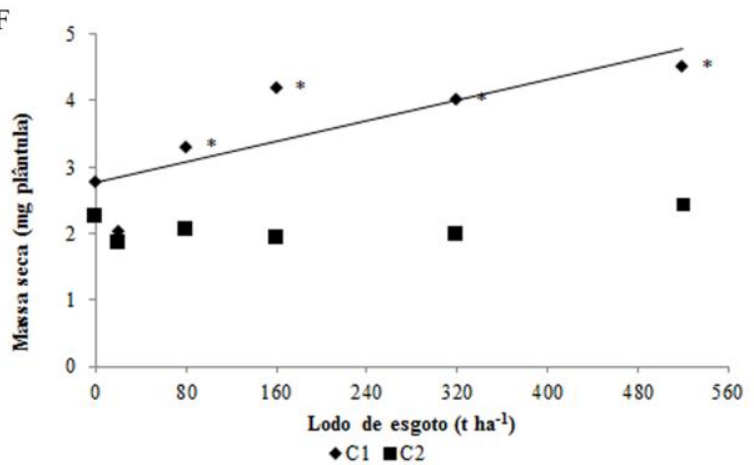

As maiores médias do comprimento da parte aérea dos cultivares 'Cereja Samambaia' e 'Cereja Carolina' foram encontradas nas concentrações de $520 \mathrm{t} \mathrm{ha}^{-1} \mathrm{e} 375 \mathrm{t} \mathrm{ha}^{-1}$, respectivamente (Figura 1C). No entanto, para comprimento de raiz, não houve diferenças entre as concentrações de lodo aplicadas (Figura 1D). O crescimento do sistema radicular é dependente dos fotoassimilados sintetizados na parte aérea da planta (GARDNER et al., 1985), enquanto o crescimento da parte aérea está associado à disponibilidade de $\mathrm{N}$ e Mg, cuja concentração no biossólido foi de 21.560 e $291,60 \mathrm{mg} \mathrm{dm}^{-3}$, respectivamente. Elementos que participam da formação das moléculas de clorofilas por complexos derivados da porfirina, que contem átomo central o $\mathrm{Mg}$, e o teor de clorofila está altamente relacionado com o teor de $\mathrm{N}$ nas plantas (TAIZ; ZEIGER, 2013). Esses resultados são similares aos obtidos por Nascimento et al. (2011), os quais verificaram que na cultura da mamoneira as plantas apresentaram crescimento linear com o aumentou da dose de lodo de esgoto até a concentração de $60 \mathrm{t} \mathrm{ha}^{-1}$.

Entretanto, considerando que dentre os cultivares houve diferença no comprimento da parte aérea e da raiz, em que o cultivar 'Cereja Carolina', apresentou as maiores médias dessas variáveis, fato que evidencia maior vigor destas sementes, principalmente, considerando que sementes vigorosas originam 
plântulas com maior taxa de crescimento, normalmente obtida de acordo com Nakagawa (1999), pela determinação do comprimento médio das plântulas normais e pela pesagem da massa seca do seu eixo embrionário.

Com relação às massas fresca e seca das plântulas verificou-se que a cultivar 'Cereja Samambaia' apresentou médias superiores o cultivar 'Cereja Carolina'. O uso do lodo de esgoto favoreceu a produção

de massa fresca e seca do cultivar 'Cereja Samambaia' nas concentrações de $362 \mathrm{t} \mathrm{ha}^{-1} \mathrm{e} 485 \mathrm{t} \mathrm{ha}^{-1}$ e para o cultivar 'Cereja Carolina', a massa fresca, na concentração de $371 \mathrm{t} \mathrm{ha}^{-1}$ (Figura 1E e F). A massa seca é uma variável que quantifica o vigor das sementes, sendo aquelas plântulas que apresentam maior massa seca consideradas com maior vigor (GAMA et al., 2010). A partir destas concentrações houve redução da produção de massas associadas ao aumento da concentração de lodo de esgoto. O aumento das massas pode estar associado ao aumento de matéria orgânica e CTC efetiva do substrato, com a liberação de nutrientes para nutrir a planta, principalmente com a aplicação de doses elevadas de lodo, conforme observado por Trannin et al. (2008) em substratos compostos por esse resíduo. Na cultura da soja, o biossólido como fonte de nutrientes apresentou-se, em média,18\% mais eficiente do que o fertilizante mineral (LEMAINSKI; SILVA, 2006). As bases trocáveis como Ca e Mg são normalmente encontradas em altas concentrações nos compostos orgânicos, que juntamente a $\mathrm{P}$ proporcionam incrementos a produção de biomassa das espécies (VIANA; KIEHL, 2010; NASCENTE et al., 2014).

Pesquisas demonstram o efeito do lodo de esgoto na produção de massas em plantas. Estudando o potencial nutricional de milho em solo tratado com lodo de esgoto, Barros et al. (2011) verificaram que o uso de biossólido favoreceu a produção de massas fresca e seca em plântulas de milho, cujos resultados foram similares aos obtidos por Oliveira et al. (2009), em plântulas de mamoneira. Similarmente, Cavallaro Júnior et al. (2009) observaram maior crescimento das plantas quando utilizaram diferentes resíduos orgânicos no cultivo do tomate e da rúcula, enquanto o uso de lodo de esgoto aumentou a produção de massa fresca em plantas de tomateiro (HOSSAIN et al.,2015) sugerindo, portanto, a necessidade de testar diferentes substratos ou misturas de substratos para cada espécie olerácea (GARAY et al., 2014).

\section{CONCLUSÃO}

As concentrações de lodo de esgoto não influenciam na emergência, velocidade de emergência e comprimento da raiz das plântulas de tomate, cultivares 'Cereja Samambaia' e 'Cereja Carolina'.

A maior produção de massa fresca e seca de plântulas ocorre com uso do lodo de esgoto na concentração entre $362 \mathrm{t} \mathrm{ha}^{-1} \mathrm{e} 485 \mathrm{tha}^{-1}$.

\section{REFERÊNCIAS}

AGRIANUAL. AGRIANUAL 2015: Anuário da agricultura brasileira. São Paulo: FNP Consultoria, 2015.472p. Disponível em: http://www.agrianual.com.br/. Acesso em: 06 abril 2016.

ALVARENGA, M. A. R. Tomate, produção em campo, casa de vegetação e hidroponia: Origem botânica e descrição da planta. $2^{a}$ Ed. Lavras. Editora Universitária de Lavras, 2013, 455p.

ALVES, E. U.et al. Substratos para testes de emergência de plântulas e vigor de sementes de Erythrina velutina Willd., Fabaceae. Semina: Ciências Agrárias, Londrina, v.29, n.1, p.69-82, 2008. Disponível em: http://www.uel.br/revistas/uel/index.php/semagrarias/article/view/2854/2422 
AMARAL, J. F. T.et al. Eficiência de utilização de nutrientes por cultivares de cafeeiro. Ciência Rural, Santa Maria, v.41, n.4, p.621-629, 2011. Disponível em:

http://www.scielo.br/scielo.php?script=sci_arttext\&pid=S0103-84782011000400012

ARAÚJO NETO, S. E.et al. Condicionadores de substrato para produção orgânica de mudas de cupuaçu. Revista Brasileira de Fruticultura, Jaboticabal, v.37, n.4, p.1083-1088, 2015. Disponível em: http://www.scielo.br/pdf/rbf/v37n4/0100-2945-rbf-37-4-1083.pdf

BARROS, I. T.et al. Avaliação agronômica de biossólidos tratados por diferentes métodos químicos para aplicação na cultura do milho. Revista Brasileira de Engenharia Agrícola e Ambiental, Campina Grande, v.15, n.6, p.630-638, 2011. Disponível em:

https://www.researchgate.net/profile/Ivan_Junior2/publication/262464277_Agronomic_evaluation_of_bio solids_treated_by_different_chemical_methods_for_cultivation_of_maize/links/5440f8460cf228087b6a36 $\underline{0 \text { c.pdf }}$

BRASIL. Ministério da Agricultura, Pecuária e Abastecimento. Secretaria de Defesa Agropecuária. Regras para análise de sementes. Brasília: Mapa/ACS. 2009. 399p. Disponível em: http://www.agricultura.gov.br/arq_editor/file/2946_regras_analise_sementes.pdf

CAVALLARO JÚNIOR, TRANI, P. E.et al. Produtividade de rúcula e tomate em função da adubação N e P orgânica e Mineral. Bragantia, Campinas, v.68, n.2, p.347-356, 2009. Disponível em: http://www.scielo.br/scielo.php?script=sci arttext\&pid=S0006-87052009000200008

CERQUEIRA, F. B.et al. Produção de mudas de tomate cv. Santa Cruz em diferentes substratos. Journal of Bioenergy and Food Science, v.2, n.2, p.39-45, 2015. Disponível em:

http://periodicos.ifap.edu.br/index.php/JBFS/article/view/21/43

Conama - Conselho Nacional Do Meio Ambiente. 2006. Resolução Conama No 375, de 29 de Agosto de 2006. Disponível em: http://www.mma.gov.br/port/conama/

DIAS, M. A.et al. Influência da temperatura e substrato na germinação de sementes de jabuticabeira (Myrciaria cauliflora Berg.). Idesia, Chile, v.29, n.1, p.23-27, 2011. Disponível em http://www.scielo.cl/scielo.php?script=sci_arttext\&pid=S0718-34292011000100004

FAO. FOOD AND AGRICULTURE ORGANIZATION OF THE UNITED NATIONS. 2015. Disponível em http://www.fao.org/brasil/parceiros/pt/. Acesso em: 05 abril 2016.

FERREIRA, R. L.et al. Temperatura inicial de germinação no desempenho de plântulas e mudas de tomate. Ciência Rural, Santa Maria, v.43, n.4, p.1189-1195, 2013. Disponível em http://www.scielo.br/scielo.php?script=sci_arttext\&pid=S0103-84782013000700008 FILGUEIRA, F. A. R. Novo manual de olericultura: agrotecnologia moderna na produção e comercialização de hortaliças. 3. ed. rev. ampl. Viçosa: UFV, 2013. 421 p.

FREITAS, A. R.et al. Emergência e crescimento de mudas de maracujá doce em função de lodo de esgoto e luz. Comunicata Scientiae, Bom Jesus, v.6, n.2, p.234-240, 2015. Disponível em http://comunicatascientiae.com.br/comunicata/article/viewFile/745/322

GAMA, J. S. N.et al. Temperaturas e substratos para germinação e vigor de sementes de Euterpe oleracea Mart. Revista Ciência Agronômica, Fortaleza, v.41, n.4, p.664-670, 2010. Disponível em http://www.scielo.br/scielo.php?script=sci arttext\&pid=S1806-66902010000400021

GARAY, C. R. E.; BOGARIN, N. B. G.; OVIEDO, V. R. S. Producción de mudas de tomate en el sistema flotante. Investigación Agraria, v.16, n.2, p.129-135, 2014. Disponível em http://www.agr.una.py/revista/index.php/ria/article/view/252

GARDNER, F. P.; PEARCE, R.B; MITCHELL, R. L. Physiology of crop plants. The Iowa State University Press, Ames, 1985. 327 p. 
HOSSAIN, M. K.; STREZOV, V.; NELSON, P. F. Comparative Assessment of the Effect of Wastewater Sludge Biochar on Growth, Yield and Metal Bioaccumulation of Cherry Tomato. Pedosphere, v.25, n.5, p.680-685, 2015. Disponível em http://www.sciencedirect.com/science/article/pii/S1002016015300485

INSTITUTO BRASILEIRO DE GEOGRAFIA E ESTATÍSTICA. Levantamento sistemático de produção agrícola, Fevereiro de 2016. Disponível em:

ftp://ftp.ibge.gov.br/Producao Agricola/Levantamento Sistematico da Producao Agricola_mensal]/Fas ciculo/lspa 201602.pdf. Acesso em 25 de março de 2016.

LEMAINSKI, J.; SILVA, J. E. Avaliação agronômica e econômica da aplicação de biossólido na produção de soja. Pesquisa Agropecuária Brasileira, Brasília, v.41, n.10, p.1477-1484, 2006. Disponível em http://www.scielo.br/scielo.php?script=sci_arttext\&pid=S0100-204X2006001000004

LOBO, T. F.; GRASSI FILHO, H.; BULL, L. T. Efeito do nitrogênio e do lodo de esgoto nos fatores produtivos do feijoeiro. Revista Ceres, v.59, n.1, p.118-124, 2012. Disponível em http://www.scielo.br/scielo.php?script=sci arttext\&pid=S0034-737X2012000100017

LOPES, J. C.et al. Broccoli production depending on the seed production system and organic and mineral fertilizer. Horticultura Brasileira, Vitoria da Conquista, v.30, n.1, p.143-150, 2012. Disponível em http://www.scielo.br/scielo.php?script=sci arttext\&pid=S0102-05362012000100024

LOPES, J. C.et al. Produção de alface com doses de lodo de esgoto. Horticultura Brasileira, Brasília, v.23, n.1, p.143-147, 2005. Disponível em http://www.scielo.br/pdf/\%0D/hb/v23n1/a30v23n1.pdf

MARCOS-FILHO, J. Fisiologia de sementes de plantas cultivadas. Piracicaba, FEALQ. 495 p., 2005.

McDONALD, M. B.; COPELAND, L. O. Seed production: principles and practices. Chapmam e Hall, 1997. 749p.

NADAI, F. B.et al. A. Produção de mudas de tomateiro em função de diferentes formas de propagação e substratos. Revista Agro@mbiente, Boa Vista, v.9, n.3, p.261, 2015. Disponível em http://www.saes2010.ufrr.br/index.php/agroambiente/article/view/2348

NAKAGAWA, J. Testes de vigor baseados na avaliação das plântulas. In: VIEIRA, R. D.; CARVALHO, N. M. Testes de vigor em sementes. Jaboticabal: FUNEP, 1999. p. 49-85.

NASCENTE, A. S.et al. Produtividade do feijoeiro comum afetada por fontes de fósforo com ou sem cálcio. Revista de Ciências Agrárias, Belém, v.57, n.2, p.180-185, 2014. Disponível em http://ainfo.cnptia.embrapa.br/digital/bitstream/item/104427/1/asn5.pdf

NASCIMENTO, A. L.et al. Crescimento e produtividade de semente de mamona tratada com lodo de esgoto. Revista Caatinga, Mossoró, v.24, n.4, p.145-151, 2011. Disponível em http://periodicos.ufersa.edu.br/revistas/index.php/sistema/article/view/2032

OLIVEIRA, J. P. B.et al. Efeito do lodo de esgoto no desenvolvimento inicial de duas cultivares de mamona em dois tipos de solos. Engenharia Ambiental - Espírito Santo do Pinhal, v.6, n.2, p.174-180, 2009. Disponível em https://www.google.com.br/url?sa=t\&rct=j\&q=\&esrc=s\&source=web $\& c d=3 \& c a d=r j a \& u a c t=8 \& v e d=0 \mathrm{ah}$ UKEwiy5 iGofvLAhXGD5AKHW6yDQ8QFggsMAI\&url=http\%3A\%2F\%2Fperiodicos.ufersa.edu.br\% 2Frevistas\%2Findex.php\%2Fsistema\%2Farticle\%2Fdownload\%2F2029\%2Fpdf\&usg=AFQjCNFfA5oyvJ 7U968b7Nu2qPg8TQjS9A\&sig2=ffAEW2FxZh1C1mgcJF3QPA\&bvm=bv.118817766,d.Y2I

PIÑA-RODRIGUES, F. C. M.et al. Parâmetros técnicos para produção de sementes florestais, Seropédica, EDUR/UFRJ, p.11-34, 2007. 
PINTO, M. A. B.et al. Aplicação de dejeto líquido de suínos e manejo do solo na sucessão aveia/milho. Pesquisa Agropecuária Tropical, Goiânia, v.44, n.2, p.205-212, 2014. Disponível em http://www.scielo.br/pdf/pat/v44n2/v44n2a02.pdf

R CORE TEAM R: A language and environment for statistical computing. R Foundation for Statistical Computing, Vienna, Austria. URL http://www.R-project.org/, 2013.

SILVA, E. C.; QUEIROZ, R. L. Formação de mudas de alface em bandejas preenchidas com diferentes substratos. Bioscience Journal, v.30, n.3, p.725-729, 2014. Disponível em http://www.scielo.br/scielo.php?script=sci_arttext\&pid=S0102-05362010000400018

SOMAVILLA, A.et al. Potencial agrícola do uso de resíduo de indústria de carnes em Latossolo Vermelho. Pesquisa Agropecuária Tropical, Goiânia, v.44, n.3, p.311-317, 2014. Disponível em http://www.scielo.br/scielo.php?script=sci_arttext\&pid=S1983-40632014000300002

TAIZ; L; ZEIGER, E. Fisiologia vegetal. 5 ed. Porto Alegre, 2013. 820 p.

TRANNIN, I. C., SIQUEIRA, J. O.; MOREIRA, F. M. S. Atributos químicos e físicos de um solo tratado com biossólido industrial e cultivado com milho. Revista Brasileira de Engenharia Agrícola e Ambiental, Campina Grande, v.12, n.3, p.223-230, 2008. Disponível em http://www.scielo.br/scielo.php?script=sci arttext\&pid=S1415-43662008000300001

VENÂNCIO, L. P.et al. Efeito do condicionador de solo Fertium® na germinação e no desenvolvimento de plântulas de pimentão. Nucleus, v.9, n.2, p.241-246, 2012. Disponível em http://www.nucleus.feituverava.com.br/index.php/nucleus/article/view/791

VIANA, E. M.; KIEHL, J. C. Doses de nitrogênio e potássio no crescimento do trigo. Bragantia, Campinas, v.69, n.4, p.975-982, 2010. Disponível em http://www.scielo.br/pdf/brag/v69n4/v69n4a24.pdf 
